\title{
"Knowledge Regarding post Operative Exercises for Clients Undergoing Cardiac Surgery Among B.Sc. Nursing Students"
}

\author{
Surendra Kumar Trivedi* \\ *Assistant Nursing Superintendent, All India Institute of Medical Sciences, Jodhpur
}

\begin{abstract}
An evaluative study to assess the effectiveness of planned teaching program on knowledge regarding post operative exercises for clients undergoing cardiac surgery among the 2 nd year b.sc nursing students was conducted in selected Nursing Colleges, at Indore(M.P.) The sample consisting of 40 B.Sc. Nursing 2nd year students were selected by using non probability purposive sampling. The tool comprised of self structured questionnaire. The pretest knowledge scores showed that majority of B.Sc. Nursing 2nd Year Students had inadequate knowledge (25\%) and (62.5\%) had moderate knowledge and only (12.5\%) had adequate knowledge regarding post operative exercises for client undergoing cardiac surgery. A planned teaching program on post operative exercises for clients undergoing cardiac surgery was developed and administered on B.Sc. Nursing 2nd year students. Post test scores were assessed. Post test scores showed a considerable increase in knowledge levels $45 \%$ students had moderate and $55 \%$ had adequate knowledge. No student was reported to have inadequate knowledge in post test scores. In relation to Planned teaching program, the paired " $t$ " test showed that, the teaching program was statistically significant at $p<0.05$ level of significance. These data proved that the knowledge of B.Sc. Nursing students had been markedly increased after the administration of planned teaching program. No significant association was found between knowledge scores and selected demographic variables of nursing students.
\end{abstract}

Keywords: Knowledge, Nursing students, Postoperative exercises, cardiac surgery.

\section{Introduction}

Coronary artery diseases continue to be a major cause of death throughout the world despite dramatic advances made in the treatment over the last 25 years. As it is growing and people are affected by it, the nurse has an important role in helping the people to live with the disease and control it through various preventive and therapeutic measures. Cardiac rehabilitation is becoming an integral part of comprehensive care of clients who have been diagnosed with CHD. It has been thought for many years that all patients, regardless of gender, or age, who have ischemic heart disease and or cardiac failure might benefit from cardiac rehabilitation.

Historically cardiac rehabilitation in early 1900's patients was kept at absolute bed rest for a minimum of 6 to 7 weeks. All voluntary movements were restricted. It was believed that minimum will go for ventricular rupture. In 1920's and 1930's, they are respected that at least 6 weeks of prolonged bed rest is required for transformation of ischemic myocardium into firm scar. In 1944, the American Medical Association in Chicago enforced for cardiac rehabilitation.

Pre- operative education is an important component in the client's operative experience. Teaching about post-operative activities is implemented in the pre-operative phase and is the nurse's main responsibility. Clients and families need to know about surgical events, and sensations, how to manage pain and how to perform physical activities necessary to decrease post operative complications and facilitate recovery. Pre-operative teaching allays anxiety and encourages clients to participate actively in their own care.An important nursing goal is patient and family education. The purpose of teaching is to give the patient and family the tools they need to make informed decisions about attainment of health. It is important for the nurses in cardiac unit to become familiar with various types of cardiac problems. If the nurse's knowledge and skill is improved the patient can get better care and health teaching by them.

These findings support the importance of providing patients with specific preoperative information about their surgery and its effect in order to minimize their post operative anxiety levels and complications.

While working in cardio-thoracic surgical ward, the investigator found that many patients undergoing cardio- thoracic surgery had inadequate knowledge about the self care. The patients were ignorant about the importance of post operative self care which includes personal hygiene, early ambulation and exercises, which helps to prevent post-operative complications. From the interaction with the patients the investigator found that the patients were anxious about surgery, postoperative pain, post operative outcome, and complications. These anxieties sometimes resulted in post operative complications and increased length of stay of patients in hospital. Considering all the above factors, the investigator developed a genuine interest and felt the need for conducting study to evaluate the effectiveness of preoperative information booklet on post operative self-care and recovery among patients undergoing cardiac surgery. 
“Knowledge regarding post operative exercises for clients undergoing cardiac surgery among B.Sc.

\section{Problem Statement:}

\section{Research Elaborations}

"An evaluative study to assess the effectiveness of planned teaching program on knowledge regarding post operative exercises for clients undergoing cardiac surgery among the $2^{\text {nd }}$ year B.Sc Nursing students in selected Nursing College, at Indore(M.P.)".

\section{Objectives}

1. To assess the level of knowledge regarding post operative exercises for clients, undergoing cardiac surgery among $2^{\text {nd }}$ year B.Sc Nursing students in selected nursing college.

2. To evaluate the effectiveness of structured teaching program on knowledge regarding post operative exercises for clients, undergoing cardiac surgery among $2^{\text {nd }}$ year B.Sc nursing students in selected nursing college.

3. To find an association between pre-test knowledge score of 2nd year B.sc nursing students with their selected demographic variables.

\section{Hypothesis}

H1: Post test knowledge score of B.Sc Nursing $2^{\text {nd }}$ year students who received planned teaching programme (PTP) regarding post operative cardiac exercises will be significantly higher than the mean pre-test knowledge score.

H2: There is a significant association between the pre test knowledge score of 2nd year BSc. Nursing students regarding post operative cardiac exercises with their selected demographical variables.

Population: B.Sc. Nursing students

\section{Materials And Methods}

Sample: B.Sc. Nursing students of Indore College of Nursing, Indore.

Sample Size: $402^{\text {nd }}$ year B.Sc. Nursing students of Indore College of Nursing, Indore

Setting: Indore College of Nursing, Indore (M.P.)

Conceptual Framework:

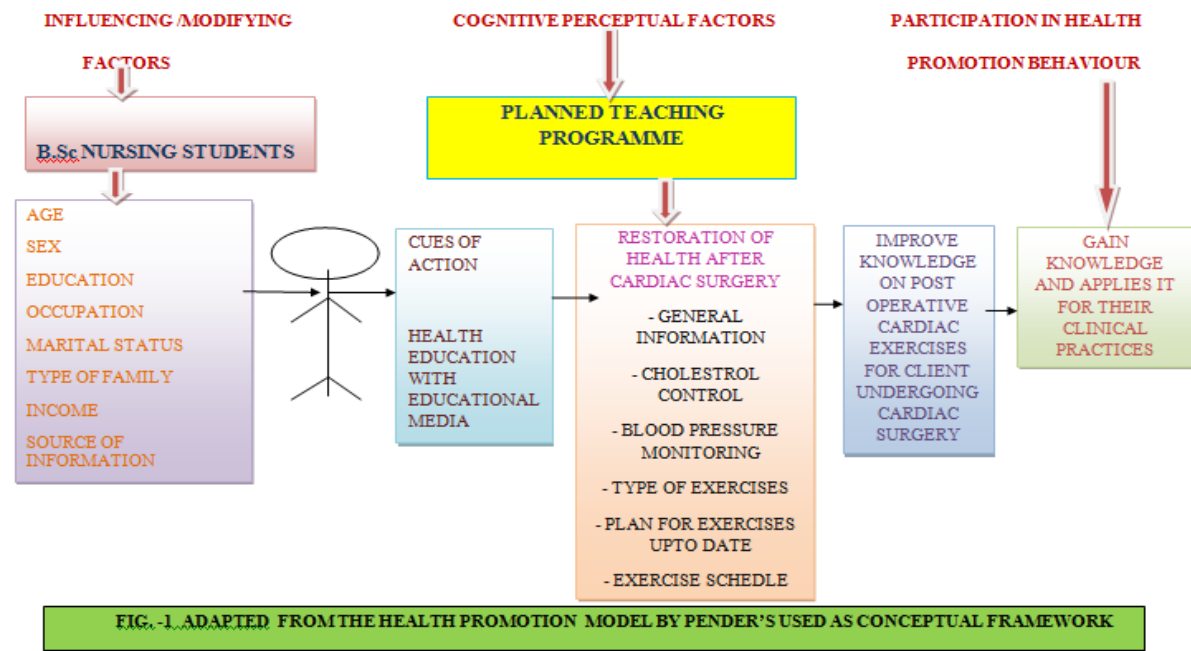

Research Design

One group pre test - post test design was used. The design is depicted below:

\begin{tabular}{|l|l|l|}
\hline Pre-Test & Intervention & Post-Test \\
\hline Day-1 & Day-1 & Day-8 \\
\hline $\mathrm{O}_{1}$ & $\mathrm{X}$ & $\mathrm{O}_{2}$ \\
\hline
\end{tabular}

$\mathbf{O}_{1}$ - Administration of Structured Knowledge Questionnaire to the nursing students on day -one

$\mathbf{X}$ - Administration of planned teaching programme on the same day.

$\mathbf{O}_{2}$ - Administration of Structured Knowledge Questionnaire after 7 days of administration of PTP.

Variables under study

Independent variable: Planned teaching program

Dependent variable: Knowledge of B.Sc Nursing students regarding post operative exercises for client undergoing cardiac surgery. 
"Knowledge regarding post operative exercises for clients undergoing cardiac surgery among B.Sc.

\section{Description of the Tool}

Section-I Personal data consists of 6 items which includes Age, Gender, Religion, Marital status and Sources of information, Monthly income (family)

Section-IIA Structured Knowledge Questionnaire was prepared consisting of 30 items of knowledge about post operative exercises for clients undergoing cardiac surgery. The items were given, one score for correct answer and zero score for wrong answer. The items were developed to cover different areas.

\section{Interpretation of Scores}

Total obtainable score was 30 . And the score was categorized as follows:

- Adequate knowledge

- Moderate knowledge

- $76 \%$ and above.

- Inadequate knowledge

- $51-75 \%$

- $50 \%$ and below.

\section{Pre test scores}

\section{Results}

Descriptive and inferential statistics were used to assess the effectiveness of the planned teaching program on the knowledge scores of B.Sc. nursing students regarding postoperative exercises for clients undergoing cardiac surgeries. The pretest score showed that the majority of B.Sc Nursing 2nd Year Students had inadequate knowledge $(25 \%)$ and $(62.5 \%)$ had moderate knowledge and only $(12.5 \%)$ had Adequate knowledge regarding post operative exercises for client undergoing cardiac surgery.

Table: 1- Area Wise Distributions Of Mean, Sd, And Mean Percentage Of Pre-Test Knowledge Score Of B.Sc Nursing $2^{\text {nd }}$ Year Students $(\mathrm{N}=40)$

\begin{tabular}{|l|l|l|l|l|l|}
\hline $\begin{array}{l}\text { Sl. } \\
\text { No }\end{array}$ & Knowledge aspects & $\begin{array}{l}\text { Max. } \\
\text { Score }\end{array}$ & Mean & Mean \% & $\begin{array}{l}\text { Standard } \\
\text { Deviation }\end{array}$ \\
\hline 1 & $\begin{array}{l}\text { Related to meaning, anatomy and physiology and } \\
\text { Introduction }\end{array}$ & 6 & 4.37 & 72.83 & 6.09 \\
\hline 2 & Related to cardiac surgery & 5 & 2.07 & 41.40 & 5.53 \\
\hline 3 & Related to cardiac diet & 3 & 1.52 & 50.67 & 5.47 \\
\hline 4 & Related to post operative cardiac exercises & 10 & 4.75 & 47.50 & 11.97 \\
\hline 5 & Health education and follow-up & 06 & 2.17 & 36.16 & 8.46 \\
\hline 6 & Over all knowledge & 30 & 14.90 & 49.67 & 25.72 \\
\hline
\end{tabular}

\section{Post test scores}

The planned teaching program was administered on the same day and the post test scores were assessed after one week. The post test scores showed that the knowledge scores have improved as compared to the pretest scores and now the majority of B.Sc. Nursing II year students had adequate knowledge $55 \%$ and $45 \%$ B.Sc Nursing II year students had moderate knowledge and no student $(0 \%)$ was under the category inadequate knowledge scores.

Table 2 : Mean, mean percentage and standard deviation for post-test knowledge scores of B.Sc nursing $2^{\text {nd }}$ year students regarding post operative exercises for clients undergoing cardiac surgery. $(\mathrm{n}=40)$

\begin{tabular}{|l|l|l|l|l|l|}
\hline $\begin{array}{l}\text { Sl. } \\
\text { No }\end{array}$ & Knowledge aspects & $\begin{array}{l}\text { Max. } \\
\text { Score }\end{array}$ & Mean & $\begin{array}{l}\text { Mean } \\
\text { percentage }\end{array}$ & $\begin{array}{l}\text { Standard } \\
\text { Deviation }\end{array}$ \\
\hline 1 & Related to meaning and Introduction & 6 & 4.80 & 80 & 6.03 \\
\hline 2 & Related to cardiac surgery & 5 & 3.6 & 72 & 6.29 \\
\hline 3 & Related to cardiac diet & 3 & 1.95 & 65 & 4.67 \\
\hline 4 & Related to post operative cardiac exercises & 10 & 7.10 & 71 & 12.55 \\
\hline 5 & Health education and follow-up & 06 & 4.12 & 68.67 & 7.23 \\
\hline 6 & Over all knowledge & 30 & 21.57 & 71.90 & 22.92 \\
\hline
\end{tabular}

Evaluating the effectiveness of planned teaching program

Table: 3 Significance Of Difference Between Overall Knowledge Scores of B.Sc Nursing 2nd Year Students

\begin{tabular}{|l|l|l|l|l|l|l|}
\hline $\begin{array}{l}\text { Overall knowledge } \\
\text { scores }\end{array}$ & $\begin{array}{l}\text { Maximum } \\
\text { Scores }\end{array}$ & Mean & $\begin{array}{l}\text { Standard } \\
\text { deviation }\end{array}$ & $\begin{array}{l}\text { Mean } \\
\text { percentage }\end{array}$ & t-Value & p-value \\
\hline PRE-TEST & 40 & 14.90 & 25.72 & 49.67 & & \\
\hline POST TEST & 40 & 21.57 & 22.92 & 71.90 & $\mathbf{1 5 . 5 7}$ & 0.05 \\
\hline
\end{tabular}




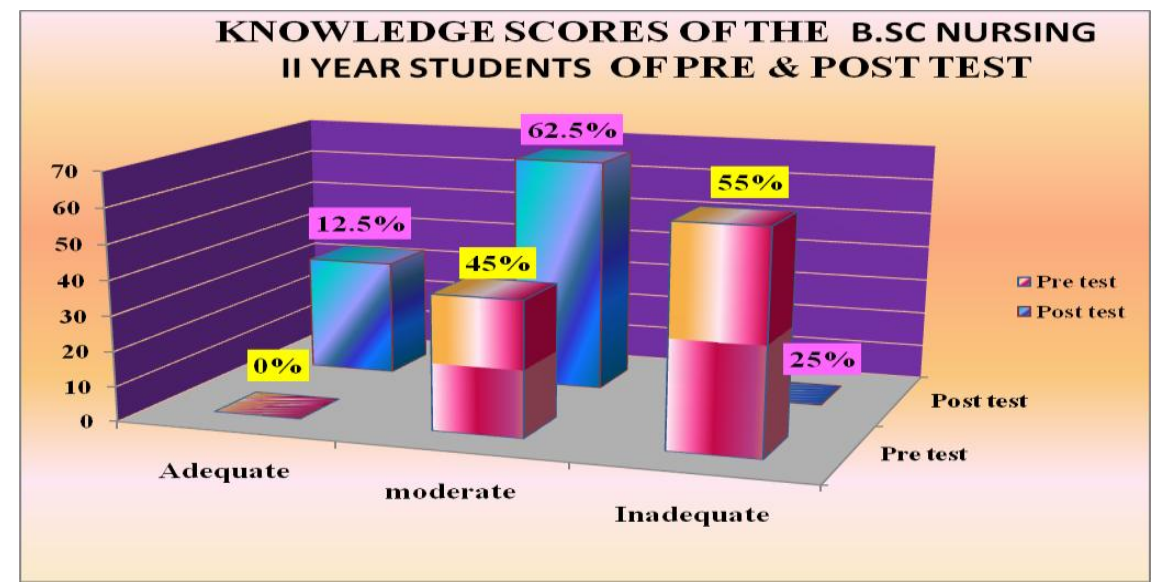

Fig 1: Comparison of pre test and post test scores

In order to determine the significance of association between the level of knowledge after the administration of PTP and the selected demographic variables, chi-square were computed from the available data. The results showed no significant association between knowledge of $2^{\text {nd }}$ Year B.Sc. Nursing Students with selected socio-demographic variables.

\section{Conclusion}

The study was done to assess the effectiveness of planned teaching program planned teaching program on knowledge regarding post operative exercises for clients undergoing cardiac surgery among the $2^{\text {nd }}$ year B.Sc Nursing students in selected Nursing College, at Indore(M.P.)".On the basis of findings it could be concluded undoubtedly that the instructional module by the investigator in the form of PTP helped the students to improve their knowledge on post operative cardiac surgery for clients undergoing cardiac surgery. Nursing students can play an important role in imparting health education to clients with cardiac surgeries which can help them to adjust better and recover fast.

\section{References}

[1]. Jhala Shah 1999, "Patterns of Cardiac disorder and epidemiology of CAD in urban population in Ahmadabad" Journals of internal Medicine Vol 2(1) Page No: 230-232.

[2]. Misra A 2005, "Atherosclerosis in Indians" Journal of Association of physicians of India 47(3), Page no 313-315

[3]. Bethell HJN, Evans JA, Turner SC, Lewin RJP. The rise \& fall of cardiac rehabilitation in the United Kingdom since 1998. Journal of Public Health (Oxf). 2006 Dec 22, [Epub ahead of print].

[4]. Nancy. A reference manual for nurses on coronary care nursing., $2^{\text {nd }}$ ed. Devai; Kumar publishing house;2002.P.18-22.

[5]. World Health Organisation.World statistics on cardiovascular diseases world health report: reducing risks, promoting healthy life Geneva:WHO,2002.

[6]. Leegaard M, Naden D, fagermoenM.SPost operative pain and self management : women's experience after cardiac surgery J Adv.Nurs 2008 sept;63(5)476-85

[7]. Willette EW, Suxxells D, Davis LL, Bush CT, (2007) Living with heart failure: patient \& carer perspectives.European Journal of Cardiovascular Nursing (In Press)

[8]. Enas (2000),'Coronary artery disease crisis” Journal of General Practice. 2006 (In Press)

[9]. Good Man (1997) "Perception of patients on their educational needs after cardiac surgery" Journal of Psychosomatic Research 2005; 59:323-329.

[10]. Kleimann CS, Nehgme RA. Cardiac arrhythmias in ICCU. Pediator Cardia 2004 May-Jun, 25(3); 234-51.

[11]. Wright L, Griffin S, Bradly F (2009) "nurses' attitudes towards this extended role, American medical journal,vol-190;2006. P: 160-6. 